\title{
Responsive Colloidosomes with Triple Function for Anticorrosion
}

\author{
Kusuma Thongchaivetcharat, Suttiruk Salaluk, Daniel Crespy,* Hélö̈se Thérien-Aubin,* \\ and Katharina Landfester
}

Cite This: ACS Appl. Mater. Interfaces 2020, 12, 42129-42139

Read Online

ACCESS | W W Metrics \& More | 国 Article Recommendations | st Supporting Information

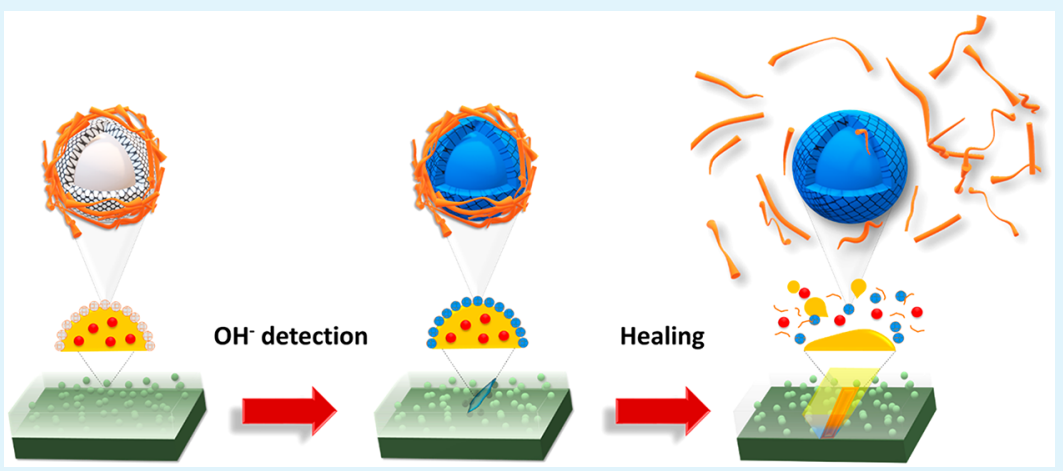

ABSTRACT: Strategies for corrosion protection are required to prolong the life span of metallic structures used by the construction, aerospace, and transport industries. Currently, there are no coatings that can provide at the same time information about the corrosion status of the coated metal and protect the metal against corrosive species and mechanical damage. Herein, triplefunctional microcarriers with functions of corrosion sensing, self-healing, and corrosion inhibition are produced and embedded in coatings to prolong the lifetime of metals and enhance the anticorrosion performance of coatings. The microcarriers are prepared by creating Pickering droplets loaded with a corrosion inhibitor and a healing agent and stabilized by silica nanocapsules containing thymol blue as corrosion sensor. The microcarriers are then embedded in a water-based polymer matrix coated on metal substrates. When the coating or metal is mechanically damaged, the healing agent is released from the droplets to hinder further corrosion of the metal. When the local $\mathrm{pH}$ value near the metal surface is changing by the generation of hydroxide ion due to the corrosion process, a change of color is detected as well as a release of corrosion inhibitor, leading to a significant decrease of corrosion rate of the coated metal.

KEYWORDS: anticorrosion, corrosion sensor, Pickering emulsion, self-healing, smart coating

\section{INTRODUCTION}

In 2015, the global annual cost of corrosion of metals was calculated to be 2.5 trillion dollars, representing $3.4 \%$ of the worldwide GDP. ${ }^{1}$ Moreover, corrosion of metals causes loss of lives, impairs product quality, and is the source of environmental issues. To overcome these problems, coatings can be applied to metals to avoid the contact of oxygen or water with metallic structures. However, coatings are deteriorating after prolonged exposure to the environment and to mechanical damages, leading to the corrosion of the underlying metals.

To extend the lifetime of the metals, so-called "smart coatings" for metallic substrates have been developed by our group and by others. A first category of smart coatings is composed of stimuli-responsive microcarriers or nanocontainers dispersed in an organic or inorganic matrix. ${ }^{2-9}$ These containers are loaded with at least one active payload, for example, a corrosion inhibitor, a corrosion sensor, or a healing agent. A second category of smart coatings is prepared from polymers containing inhibitors or healing agents linked to the polymer main chain by labile bonds. ${ }^{10,11}$ Both categories of materials are responsive to changes of $\mathrm{pH}$ value or redox conditions originating from the corrosion of the metal or from mechanical damage such as cracks. ${ }^{12}$

To extend the lifetime of coated metallic structures, a combination of self-healing and corrosion inhibition or sensing can be implemented in the same coating. ${ }^{13-16}$ The combination of functions can be realized by dispersing two or more types of containers in the same matrix. An epoxy coating containing 5 wt $\%$ nanocontainers loaded with an inorganic inhibitor and 5 wt \% microcapsules containing a healing agent was successfully used for the protection of mild

Received: June 30, 2020

Accepted: August 25, 2020

Published: August 25, 2020 
steel from corrosion. ${ }^{17}$ Indeed, the epoxy coating containing both nanocontainers and microcapsules exhibited a 3-fold better corrosion resistance $\left(R=1649 \mathrm{k} \Omega \cdot \mathrm{cm}^{2}\right)$ than the coating containing only the microcapsules $\left(R=550 \mathrm{k} \Omega \cdot \mathrm{cm}^{2}\right)$.

Similarly, self-healing and corrosion sensing features have been combined in one coating to both reduce the corrosion of metals after mechanical damage and allow the early detection of corrosion or that the coating is critically damaged. ${ }^{18-20}$ However, loading a coating's matrix with different types of containers can lead to an irregular distribution of containers throughout the coating, hence yielding inhomogeneity in the performance of the coatings. $^{21}$

To overcome the issues associated with the possible uneven distribution of different additives mixed in one coating using different carriers, the functionalities of healing, inhibition, or sensing can be combined in one single container. ${ }^{12}$ Leal et al. prepared polyelectrolyte multilayer microcapsules (with a diameter of $\sim 2 \mu \mathrm{m}$ ) containing both linseed oil and benzotriazole. $^{22}$ When the capsules were embedded in an epoxy coating, the release of linseed oil and benzotriazole enabled the protection of coated carbon steel. The layer-bylayer deposition technique on nano- or microtemplates is, however, difficult to scale up. Therefore, we also aimed at developing smart coatings that can be produced in large scale. $^{23}$

Colloidosomes or Pickering emulsions are emulsions stabilized by solid particles and can be used to produce large amounts of emulsions. Silica nanocapsules were recently used as Pickering stabilizers to stabilize polyacrylate particles. ${ }^{24}$ Pickering emulsions have also been employed to prepare materials for anticorrosion. ${ }^{25-27}$ UV-responsive microcapsules containing dodecafluoroheptylpropyltrimethoxysilane, which were stabilized with titania and silica nanoparticles, were prepared from Pickering emulsions. ${ }^{28}$ The hydrophobic alkoxysilane was released from the capsules after abrasion cycles to recover the superhydrophobicity of the coating, preventing the penetration of water into the coating. An epoxy coating containing isophorone diisocyanate Pickering emulsions stabilized with lignin nanoparticles was applied on steel plates, resulting in the inhibition of corrosion after $120 \mathrm{~h}$ immersion in a strongly saline solution. ${ }^{29}$ Although several reports mentioned Pickering emulsions for anticorrosion application, there has been no report on a $\mathrm{pH}$-responsive Pickering emulsion or emulsions displaying triple functions for corrosion protection. Herein, a coating containing triplefunctional microcarriers is created for the first time from Pickering emulsions. Droplets loaded with a corrosion inhibitor and a self-healing agent were stabilized with silica nanocapsules loaded with a corrosion sensor, forming a stable Pickering emulsion dispersible in waterborne polymer coatings.

\section{EXPERIMENTAL SECTION}

Materials. Tetraethyl orthosilicate (TEOS, Sigma-Aldrich, 98\%), $n$-hexadecane (HD, Alfa Aesar, 99\%), thymol blue (TMB, SigmaAldrich), hexadecyltrimethylammonium bromide (CTAB, SigmaAldrich, $\geq 99 \%$ ), chitosan (CS, low molecular weight, Sigma-Aldrich), alginic acid sodium salt from brown algae (ALG, low viscosity, SigmaAldrich), $1 H$-benzotriazole (BTA, Fluka, $>99 \%$ ), soybean oil (SigmaAldrich), linseed oil (Carl Roth GmbH), methyl methacrylate (MMA, Acros Organics, 99\%), butyl acrylate (BA, Acros Organics, >99\%), potassium persulfate (KPS, Merck), Lutensol AT50 (BASF), Nile blue A (Sigma-Aldrich, $\geq 75 \%$ ), coumarin 6 (Sigma-Aldrich, 98\%), copper sheet (SF-Cu, Jeddeloh, Germany), hydrochloric acid ( $\mathrm{HCl}$, Sigma-Aldrich), sodium chloride ( $\mathrm{NaCl}$, Carl Roth $\mathrm{GmbH}, \geq 99.5 \%)$, sodium hydroxide $(\mathrm{NaOH}$, Sigma-Aldrich, >98\%), acetic acid (AcOH, VWR), 1-butanol (BuOH, Fisher Chemical, $\geq 99.5 \%)$, tetrahydrofuran (THF, Fisher Chemical, $\geq 99.8 \%$ ), and $n$-hexane (Fisher Chemical, $\geq 95 \%$ ) were used as received. The water used was deionized.

Synthesis of Silica Nanocapsules with Encapsulated Thymol Blue ( $\left.\mathrm{SiO}_{2} \mathrm{NCs}-\mathrm{TMB}\right)$. A $100 \mathrm{~g}$ aliquot of a 0.077 wt \% $\mathrm{CTAB}$ aqueous solution was added into solutions containing $5 \mathrm{~g}$ of TEOS, $210 \mathrm{mg}$ of HD, $50 \mathrm{mg}$ of TMB, $2.5 \mathrm{~g}$ of butanol, and $5 \mathrm{mg}$ of Nile blue A. The mixture was stirred at $500 \mathrm{rpm}$ for $10 \mathrm{~min}$ at $20^{\circ} \mathrm{C}$. Afterward, the mixture was pre-emulsified (T18 digital ultra-turrax, IKA, Germany) at $20000 \mathrm{rpm}$ for $30 \mathrm{~s}$. The resulting emulsion was then further processed with a microfluidizer (LM10, Microfluidics Corporation, USA) equipped with a Y-shaped interaction chamber (F20Y) operated at 10000 psi for two cycles to obtain the final miniemulsions. The miniemulsions were then stirred at $500 \mathrm{rpm}$ for $20 \mathrm{~h}$ to carry out the sol-gel process. After $20 \mathrm{~h}$, a light orange dispersion was obtained. The dispersion was dialyzed (molecular weight cutoff $=12000-14000 \mathrm{~g} \mathrm{~mol}^{-1}$ ) for 1 day to remove free $\mathrm{CTAB}$. One gram of the nanocapsule dispersion was centrifuged at $30000 \mathrm{rpm}$ for $30 \mathrm{~min}$. A $0.5 \mathrm{~g}$ sample of supernatant was mixed with $0.5 \mathrm{~g}$ of ethanol. Then, $0.5 \mathrm{~g}$ of the mixture was added into $2.5 \mathrm{~g}$ of a water:ethanol ( $\mathrm{v}: \mathrm{v}=1: 1)$ mixture. The concentration and encapsulation efficiency of TMB were measured by UV-vis spectroscopy at a wavelength of $440 \mathrm{~nm}$.

Functionalization of the Nanocapsules with Polymers. A $0.1125 \mathrm{~g}$ sample of chitosan or alginate was added into $10 \mathrm{~g}$ of a dispersion containing $1.5 \mathrm{wt} \%$ of silica nanocapsules $\left(\mathrm{SiO}_{2} \mathrm{NCs}-\right.$ $\mathrm{TMB}$ ) and stirred at $500 \mathrm{rpm}$ for $30 \mathrm{~min}$. Afterward, the homogeneous mixture was adjusted to $\mathrm{pH} 3$ by using $0.1 \mathrm{M} \mathrm{HCl}$ and $0.1 \mathrm{M} \mathrm{NaOH}$ aqueous solutions. Dispersions of chitosan- or alginate-coated $\mathrm{SiO}_{2} \mathrm{NCs}$-TMB were then obtained.

Preparation of Pickering Emulsions Stabilized with Nanocapsules. A $2.5 \mathrm{~g}$ sample of soybean oil, linseed oil, or linseed oil containing $67.5 \mathrm{mg}$ of BTA was added to $5 \mathrm{~g}$ of a chitosan- or alginate-coated $\mathrm{SiO}_{2} \mathrm{NCs}-\mathrm{TMB}$ dispersion. Then, the mixture was stirred at $1000 \mathrm{rpm}$ for $10 \mathrm{~min}$. Emulsification was subsequently processed twice at $7500 \mathrm{psi}$ by a microfluidizer (LV1, Microfluidics Corporation, USA) equipped with a Z-shaped interaction chamber $(\mathrm{H} 210 \mathrm{Z})$ to produce oil-in-water Pickering emulsions.

Synthesis of the Acrylate Dispersion. The dispersion for the acrylate coating was prepared following a previous report. ${ }^{30}$ A mixture of $17 \mathrm{~mL}$ of MMA, $18 \mathrm{~mL}$ of BA, and $1.55 \mathrm{~mL}$ of $\mathrm{HD}$ was added into $64 \mathrm{~mL}$ of water containing of $800 \mathrm{mg}$ of Lutensol AT50 and $80 \mathrm{mg}$ of KPS and stirred at $1000 \mathrm{rpm}$ for $1 \mathrm{~h}$. Afterward, the pre-emulsion was ultrasonicated (Branson sonifier W450, 1/2 in. tip) under ice cooling at $70 \%$ amplitude with pulses ( $30 \mathrm{~s}$ on, $10 \mathrm{~s}$ off) for $2 \mathrm{~min}$. The miniemulsion was poured into a $100 \mathrm{~mL}$ round-bottom flask and then purged with argon for $10 \mathrm{~min}$ before polymerization. The polymerization was performed at $80{ }^{\circ} \mathrm{C}$ for $20 \mathrm{~h}$ to obtain the dispersion of poly(methyl methacrylate-co-butyl acrylate) (P(MMA-co-BA $)$ ) with $33 \%$ solid content.

Release Experiment of Benzotriazole (BTA) from Pickering Droplets in the Coating. We mixed 5 wt \% of linseed oil Pickering droplets loaded with BTA to the dispersion of P(MMA-co-BA) by stirring at $250 \mathrm{rpm}$ for $30 \mathrm{~min}$. One gram of the mixture was drop-cast on a glass slide and dried at $20{ }^{\circ} \mathrm{C}$ for $12 \mathrm{~h}$. The coated glass slides were immersed into $100 \mathrm{~mL}$ of $0.1 \mathrm{M}$ phosphate buffer solutions at $\mathrm{pH} 3,7$, or 11 . Then, $1 \mathrm{~mL}$ of the release medium was collected at different time intervals and replaced with $1 \mathrm{~mL}$ of fresh buffer solution. The collected medium of released BTA was measured by a

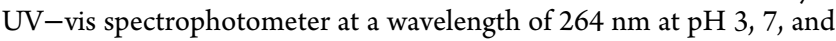
$275 \mathrm{~nm}$ at $\mathrm{pH}$ 11. The calibration curves were plotted at a BTA concentration of 5-25 ppm at $\mathrm{pH}$ values of 3,7 , and 11 .

Investigation of the Self-Healing Process. One gram of $\mathrm{P}(\mathrm{MMA}-\mathrm{co}-\mathrm{BA})$ dispersion and $\mathrm{P}(\mathrm{MMA}-\mathrm{co}-\mathrm{BA})$ dispersion mixed with 15 wt $\%$ of soybean oil or linseed oil Pickering droplets were coated by drop-casting method on $3 \times 3 \mathrm{~cm}^{2}$ glass slides. A scratch with a length of $1 \mathrm{~cm}$ was performed on the dried coating by using a razor blade. The evolution in time of the scratch was monitored by 


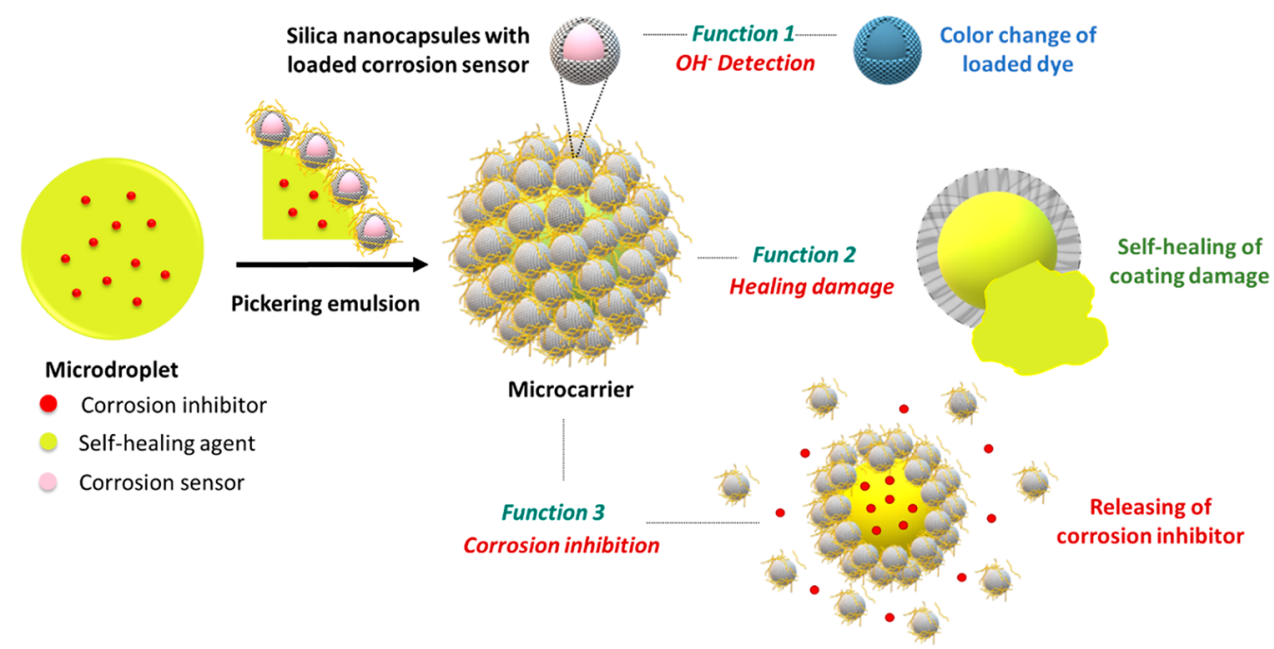

Figure 1. Scheme of multifunctional Pickering emulsions and their response to mechanical damage or $\mathrm{pH}$ change.

optical microscopy (OM, Leica DM 2700 P, Leica Microsystems) with a $10 \times$ objective. Once the coating was healed, the coated glass slide was immersed in $30 \mathrm{~mL}$ of hexane for $5 \mathrm{~min}$, and then the scratched area on the coating was observed again with an optical microscope.

Preparation of the Coatings on Copper Substrates. Prior to the application of the coating, copper substrates (99.95\% purity) with an area of $3 \times 3 \mathrm{~cm}^{2}$ were polished with a semiautomatic machine (Phoenix 4000, Buehler GmbH, Germany) with 320, 600, and 1200 grit $\mathrm{SiC}$ abrasive paper and cleaned with isopropanol. A $500 \mu \mathrm{L}$ aliquot of the $\mathrm{P}$ (MMA-co-BA) dispersion was coated as a primer by spin-coating (EC101D spinner, Headway research, Inc., USA) at 3000 $\mathrm{rpm}$ for $1 \mathrm{~min}$, and the primer was then dried at $20{ }^{\circ} \mathrm{C}$ for $30 \mathrm{~min}$. Afterward, $1 \mathrm{~g}$ of either $\mathrm{P}$ (MMA-co-BA) dispersion, $\mathrm{P}$ (MMA-co-BA) dispersion mixed with ALG-coated $\mathrm{SiO}_{2} \mathrm{NCs}-\mathrm{TMB}, \mathrm{P}$ (MMA-co-BA) dispersion mixed with 15 wt $\%$ of linseed oil Pickering droplets, or $\mathrm{P}$ (MMA-co-BA) dispersion mixed with 15 wt \% of linseed oil Pickering droplets with loaded BTA was drop-cast on the primer layer. The coated substrates were dried at $20{ }^{\circ} \mathrm{C}$ for $12 \mathrm{~h}$. The thickness of the coating, ca. $270-300 \mu \mathrm{m}$, was then recorded with an electronic digital micrometer (VWR, Germany).

Corrosion Tests. The coatings were cut with two $1 \mathrm{~cm}$ long incisions in an X-shape. Afterward, the coated substrates were immersed in $3.5 \mathrm{wt} \% \mathrm{NaCl}$ aqueous solution and were monitored visually with time. The potentiodynamic polarization measurements were performed on the coated substrates covering their edges with a polyester film tape to leave an open area of $1 \times 1 \mathrm{~cm}^{2}$.

Characterization. The sizes of $\mathrm{SiO}_{2} \mathrm{NCs}-\mathrm{TMB}$ were measured by dynamic light scattering (DLS, Nano-S90, Malvern). The $\zeta$ potentials of $\mathrm{SiO}_{2} \mathrm{NCs}$-TMB and polymer-coated $\mathrm{SiO}_{2} \mathrm{NCs}$-TMB were measured on a Zetasizer (Nano-Z, Malvern). The morphology of $\mathrm{SiO}_{2} \mathrm{NCs}$-TMB was observed by transmission electron microscopy (TEM, JEM 1400, JEOL) at an acceleration voltage of $120 \mathrm{kV}$. The surface tension of polymer-coated $\mathrm{SiO}_{2} \mathrm{NCs}$-TMB dispersions at different $\mathrm{pH}$ values was measured with the du Noüy ring technique (DCAT 11, Dataphysics) to identify suitable conditions for preparing the Pickering emulsions. To confirm the stability of $\mathrm{SiO}_{2} \mathrm{NCs}-\mathrm{TMB}$ after microfluidization, $1 \mathrm{~mL}$ of the Pickering emulsions was washed with $10 \mathrm{~mL}$ of THF and centrifuged (3-30K, Sigma) at $10000 \mathrm{rpm}$ for $5 \mathrm{~min}$ to separate the dispersed and continuous phases. The pellet was dried in an oven at $90{ }^{\circ} \mathrm{C}$ for $15 \mathrm{~h}$. Afterward, the dried samples were coated on carbon tape and observed with a scanning electron microscope (SEM, Gemini 1530, LEO). The morphologies of Pickering emulsions and Pickering droplets in the coating were investigated by confocal laser scanning microscopy (CLSM, TCS SP5, Leica Microsystems). Fluorescence images of Pickering emulsions and embedded Pickering droplets in the coating were taken on glass slides with a $63 \times \mathrm{NA} 1.2$ water immersion objective at an excitation wavelength of 458 and $488 \mathrm{~nm}$ for coumarin 6 and $633 \mathrm{~nm}$ for Nile blue A. The average diameter of the droplets in the Pickering emulsions was calculated from the measurements of 100 independent droplets observed by CLSM. The release of BTA was measured with a UV-vis spectrophotometer (Cary 60, Agilent Technologies). The healing process of the composite coatings was monitored with an optical microscope (OM, Leica DM 2700 P, Leica Microsystems) equipped with a $10 \times$ objective. Raman spectroscopy (QEPro, Ocean Optics) with a $785 \mathrm{~nm}$ laser source was used for quantifying the selfhealing process; the quantification was realized by comparing the area of the $\mathrm{C}=\mathrm{C}$ vibration at $1654 \mathrm{~cm}^{-1}$ (between 1615 and $1695 \mathrm{~cm}^{-1}$ ) to the integration of the $\mathrm{C}=\mathrm{O}$ vibration at $1730 \mathrm{~cm}^{-1}$ (between 1710 and $1760 \mathrm{~cm}^{-1}$ ). For the investigation of the stability of the Pickering droplets of linseed oil in the acrylate matrix, coatings stored for 1, 5, and 10 days at $\sim 25{ }^{\circ} \mathrm{C}$ and $\sim 67 \%$ humidity were scratched (five parallel scratches of $50 \mathrm{~mm}$ length) with a razor blade $(0.38 \mathrm{~mm}$ thick) and left to heal for 1 day at $\sim 25{ }^{\circ} \mathrm{C}$ and $\sim 67 \%$ humidity. The coatings were then investigated by Raman spectroscopy with a 785 nm laser source (Senterra II, R200-532, Bruker).

The electrochemical measurements were performed with a potentiostat (Autolab PGSTAT204, Metrohm). The electrodes were a treated copper substrate as the working electrode, a $\mathrm{Ag} /$ $\mathrm{AgCl}$ in $3 \mathrm{M} \mathrm{KCl}$ reference electrode, and a platinum counter electrode. The measurements were performed at $20^{\circ} \mathrm{C}$ in a $3.5 \mathrm{wt} \%$ $\mathrm{NaCl}$ aqueous solution. The polarization curves were observed after a $30 \mathrm{~min}$ equilibrium in an open-circuit potential (OCP) configuration. The potential was scanned from -1 to $1 \mathrm{~V}$ with a scan rate of $1 \mathrm{mV}$ $\mathrm{s}^{-1}$. Tafel plots were extrapolated to determine corrosion potential $\left(E_{\text {corr }}\right)$, corrosion current density $\left(j_{\text {corr }}\right)$, polarization resistance $\left(R_{\mathrm{p}}\right)$, and corrosion rate $(\mathrm{CR})$ by using the Nova version 2.1 software. The $\mathrm{CR}$ was calculated by multiplying the equivalent weight of copper $\left(31.78 \mathrm{~g} \mathrm{~mol}^{-1}\right)$ with current density of tested copper $\left(j_{\text {corr }}, \mu \mathrm{A} / \mathrm{cm}^{2}\right)$ and the conversion factor $\left(K=327.2 \mathrm{~A}^{-1}\right.$ year $\left.^{-1}\right)$ divided by the copper density $\left(\rho=8.94 \mathrm{~g} \mathrm{~cm}^{-3}\right){ }^{31}$ Electrochemical impedance spectroscopy (EIS, Autolab PGSTAT302N, Metrohm) was performed in a $3.5 \mathrm{wt} \% \mathrm{NaCl}$ aqueous solution with a FRA potential scan mode within the frequency range of $100 \mathrm{kHz}-10 \mathrm{mHz}$ and a perturbation voltage of $10 \mathrm{mV}$. Copper substrates were used as the working electrode, while the $\mathrm{Ag} / \mathrm{AgCl}$ reference electrode and platinum counter electrode were assembled to prepare a corrosion test cell. EIS results were analyzed by NOVA version 2.1 software. Electrochemical impedance spectra were measured on the copper substrates coated with an acrylate coating, the acrylate coating containing 45 wt \% of linseed oil Pickering droplets, or the acrylate coating containing 45 wt \% of linseed oil Pickering droplets loaded with benzotriazole. The edges of the coated copper substrates were covered with a polyester film tape to leave an open area of $1 \times 1 \mathrm{~cm}^{2}$. 
The exposed area of coated copper was cut along a vertical length of $50 \mathrm{~mm}$ with a razor blade.

\section{RESULTS AND DISCUSSION}

We designed microcarriers consisting of Pickering microdroplets stabilized by nanocapsules with the triple functions of sensing, self-healing, and corrosion inhibition. We selected microcontainers since it is known that self-healing performance of containers increases with the size of the containers at a constant fraction of containers in a matrix and that, consequently, a microcontainer can be more efficient than nanocontainers in such applications. ${ }^{32}$ Furthermore, we used Pickering droplets as the templates for fabricating the microcontainers because a container with a low stiffness, like those Pickering microcontainers, tend to drive the cracks toward the microcapsules whereas stiffer containers with large thickness deflected cracks away, hence preventing the healing of the damaged area. ${ }^{33}$ The microcontainers were designed to contain a corrosion sensor in the nanocaspules used as Pickering stabilizers for microdroplets loaded with one corrosion inhibitor and one healing agent (Figure 1). After the microcontainers were embedded in a matrix and coated on a metal substrate, the corrosion sensor and corrosion inhibitor were programmed to be released upon $\mathrm{pH}$ change $(\mathrm{pH}>10)$ while the healing agent can be released after mechanical damage.

To both stabilize Pickering droplets and encapsulate a corrosion sensor, silica nanocapsules were prepared by a solgel process in a miniemulsion. Corrosion detection occurred through the sensing of the change in the local $\mathrm{pH}$ value. Indeed, when a metal is corroded, the $\mathrm{pH}$ value at the local cathodic site increases due to the generation of hydroxide ions. During the corrosion of copper, $\mathrm{pH}$ values of 11.2 were observed near the metal surface. ${ }^{34}$ Thymol blue (TMB), a common $\mathrm{pH}$ indicator, can be used as a sensor to track the corrosion of copper. Indeed, TMB is red at $\mathrm{pH} 1.2$ in aqueous

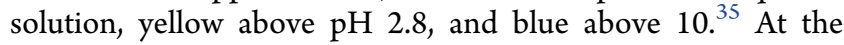
cathodic site, the yellow TMB can therefore turn blue during the corrosion of the metals. ${ }^{35-37}$ TMB (2.8 wt \%/nanocapsules) was entrapped in silica nanocapsules $\left(\mathrm{SiO}_{2} \mathrm{NCs}-\right.$ TMB) with an encapsulation efficiency of $84 \%$ by a sol-gel reaction in miniemulsion. Nanocapsules with a well-defined core-shell structure were formed, as observed by transmission electron microscopy (TEM) measurements (Figure S1). The average hydrodynamic diameter of $\mathrm{SiO}_{2} \mathrm{NCs}-\mathrm{TMB}$ was $81 \pm 4$ $\mathrm{nm}$. These nanocapsules were then used for the stabilization of Pickering emulsion microdroplets, resulting in the preparation of functional microcontainers.

The microdroplets stabilized with the $\mathrm{SiO}_{2} \mathrm{NCs}-\mathrm{TMB}$ were mainly composed of linseed oil, which was used as a selfhealing agent. Linseed oil was selected because it is an environmentally friendly and biobased molecule, which can be polymerized by oxidation in air, leading to the formation of solid films. ${ }^{38-40}$ The linseed oil is therefore expected to be released and solidified after the mechanical rupture of the microcontainers. Finally, benzotriazole (BTA), a corrosion inhibitor, ${ }^{41}$ which can be chemisorbed on copper substrates via its azole moiety and physisorbed via the aromatic ring, ${ }^{42}$ was dissolved in linseed oil forming the Pickering droplets.

The stability of the Pickering emulsion was optimized by using silica nanocapsules $\left(\mathrm{SiO}_{2} \mathrm{NCs}\right)$ with various diameters and concentrations. However, the creaming of the Pickering emulsions was observed in all conditions (Figure S2). Thus, the silica nanocapsules were hydrophobized by the adsorption of polymers ${ }^{43-45}$ to prepare Pickering emulsions with longterm stability. Chitosan (CS) and alginate (ALG) are weak polyelectrolytes that are charged through the protonation of amino groups $\left(\mathrm{p} K_{\mathrm{a}} \sim 6.3\right)^{46}$ for chitosan and the deprotonation of carboxylic acid groups $\left(\mathrm{p} K_{\mathrm{a}} \sim 4.25\right)^{47}$ for alginate. Various amounts of CS or ALG were added to the dispersions of $\mathrm{SiO}_{2} \mathrm{NCs}$ with an average diameter of $80 \mathrm{~nm}$. When the concentrations of the polymer were increased from 0.3 to 7.5 wt \% relative to the silica nanocapsules, homogeneous and stable Pickering emulsions were obtained (Figure S2).

The complexation of CS or ALG with the $\mathrm{SiO}_{2} \mathrm{NCs}$ was realized under different conditions to tune the final properties of the polymer-coated silica NCs. The resulting polymercoated silica NCs were monitored by measuring the $\zeta$ potential of the colloids as well as the surface tension of the emulsions (Figure 2 and Figure S3). The acidity of the environment has

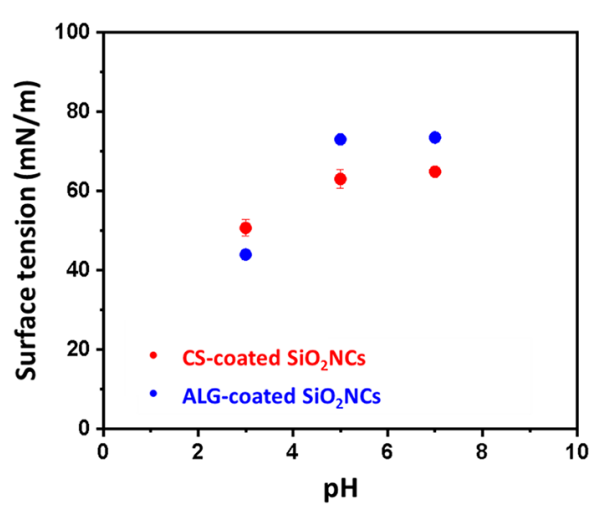

Figure 2. Surface tension of aqueous suspensions (3 wt \%) of polymer-coated silica nanocapsules at $\mathrm{pH} 3,5$, and 7 .

been shown to influence the adsorption of chitosan on silica particles and controlling the stabilization of Pickering emulsions. ${ }^{45}$ The adsorption of the polyelectrolytes (CS and $\mathrm{ALG}$ ) was performed at various $\mathrm{pH}$ values $(3,5,7,9$, and 11). At $\mathrm{pH} 9$ and 11, CS is not charged while ALG is negatively charged, and no adsorption of polymers on silica surface occurred. Thus, the $\zeta$ potential (Figure S3) remained similar to the $\zeta$ potential of pristine $\mathrm{SiO}_{2} \mathrm{NCs}(\sim-40 \mathrm{mV})$. When the coating of the $\mathrm{SiO}_{2} \mathrm{NCs}$ with $\mathrm{CS}$ was performed at a $\mathrm{pH}$ value of 5 , the $\zeta$ potential increased from -3 to $12 \mathrm{mV}$. Similarly, when the coating was performed at $\mathrm{pH} 7$, the $\zeta$ potential increased from -20 to $-5 \mathrm{mV}$. These $\mathrm{pH}$ values are closed to the $\mathrm{p} K_{\mathrm{a}}$ of CS, which was adsorbed on the negatively charged silica surface. Because of the adsorption of CS on the silica surface, the surface tensions of $\mathrm{SiO}_{2} \mathrm{NCs}$ at $\mathrm{pH} 5$ and 7 were 63.0 and $64.9 \mathrm{mN} \mathrm{m}^{-1}$, respectively. At $\mathrm{pH} \mathrm{3,} \mathrm{CS} \mathrm{could} \mathrm{be}$ adsorbed on the surface of $\mathrm{SiO}_{2} \mathrm{NCs}$, as confirmed by the decreasing of surface tension to $50.7 \mathrm{mN} \mathrm{m}^{-1}$ and the increasing of $\zeta$ potential from 9 to $20 \mathrm{mV}$. ALG was partially negatively charged, leading to the adsorption of ALG on the positively charged $\mathrm{SiO}_{2} \mathrm{NCs}$ at $\mathrm{pH} 3$. The $\zeta$ potential of $\mathrm{SiO}_{2} \mathrm{NCs}$ coated with ALG was reduced from 9 to $-13 \mathrm{mV}$, and the surface tension of $\mathrm{SiO}_{2} \mathrm{NCs}$ coated with ALG was 44.0 $\mathrm{mN} \mathrm{m}^{-1}$. Thus, both CS- and ALG-coated $\mathrm{SiO}_{2} \mathrm{NCs}$ were suitable for stabilizing Pickering emulsions at $\mathrm{pH} 3$ (Figure S4). 

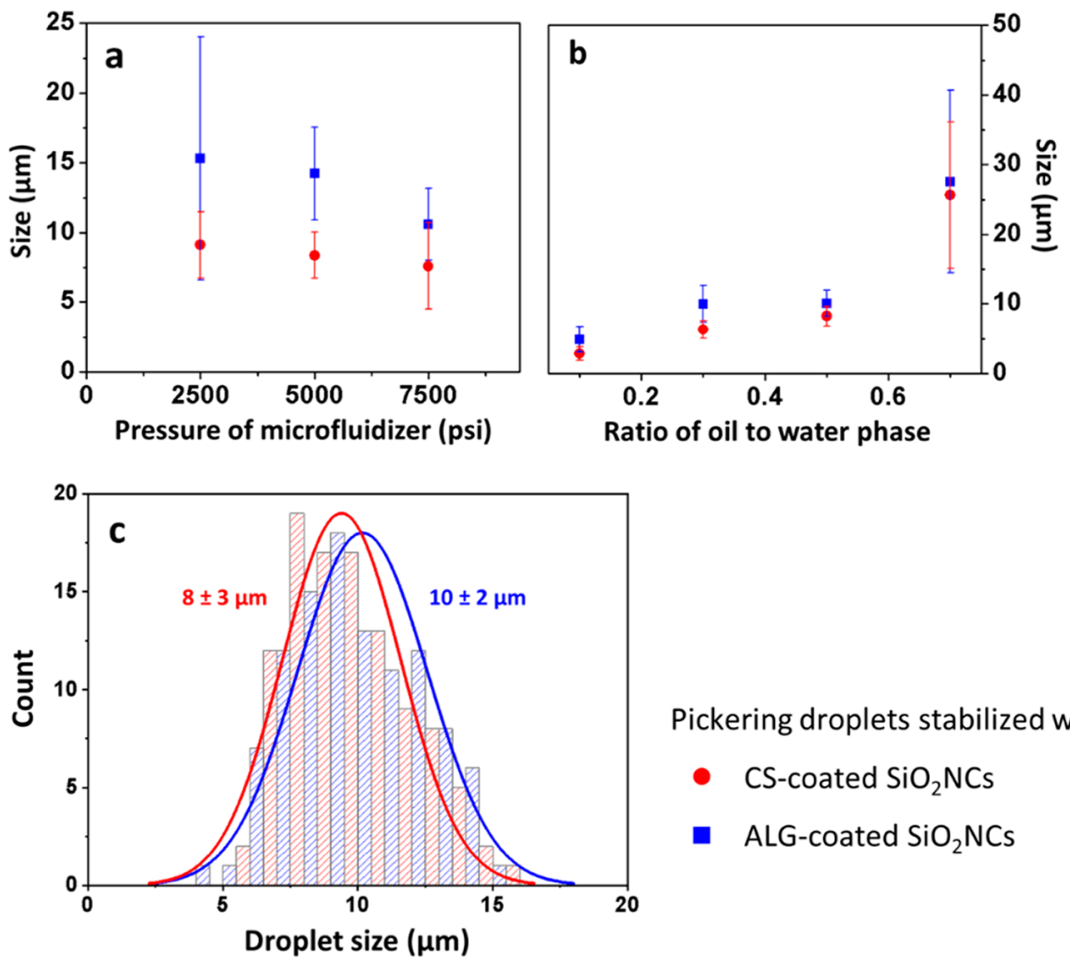

Pickering droplets stabilized with

- CS-coated $\mathrm{SiO}_{2} \mathrm{NCS}$

- ALG-coated $\mathrm{SiO}_{2} \mathrm{NCs}$

\section{d Excitation wavelength $(\mathrm{nm})$}

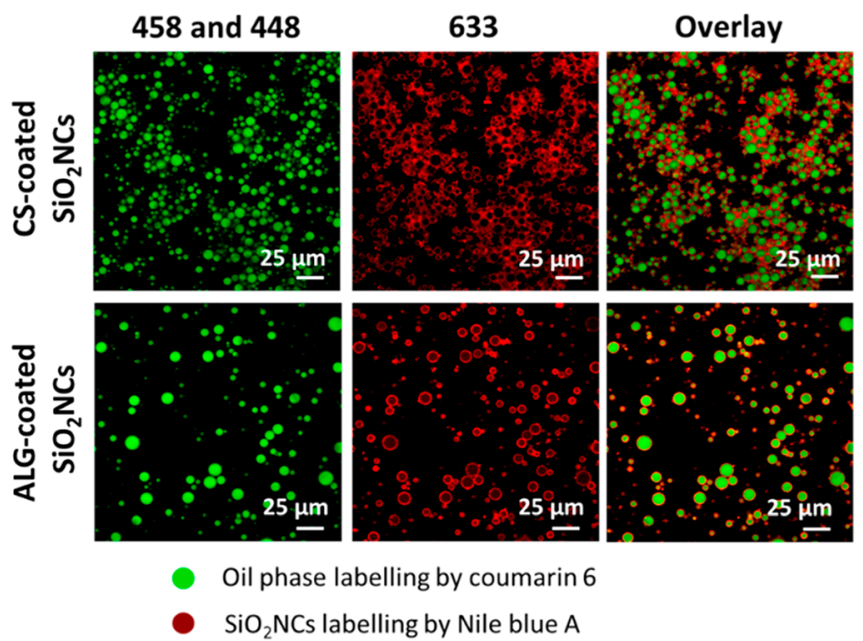

Figure 3. Average diameter of Pickering emulsions with (a) increasing applied pressure for a mixture of 1:2 oil:water and (b) increasing weight ratio of oil to water emulsified at a pressure of 7500 psi. (c) Size distributions measured by counting the diameter of 100 droplets on CLSM images for emulsion prepared with 1:2 oil:water at a pressure of 7500 psi. (d) Fluorescence images of the Pickering droplets prepared with an oil:water ratio of 1:2 at a pressure 7500 psi. The oil was labeled with coumarin 6 (green), while the silica nanocapsules dispersed in water were labeled with Nile blue A (red).

Microfluidization was used to prepare the Pickering emulsion by using the polymer-coated $\mathrm{SiO}_{2} \mathrm{NCs}$. Controlling the ratio of linseed oil to water containing the $\mathrm{SiO}_{2} \mathrm{NCs}$ and the shear force applied to this binary mixture in the microfluidizer by tuning the pressure applied to accelerate the flow of the water and oil mixture resulted in the precise control of the final size of the Pickering emulsion (Figure 3a). Controlling the ratio of oil to water used influenced not only the size of the Pickering emulsion droplets (Figure 3b) but also the presence of free $\mathrm{SiO}_{2} \mathrm{NCs}$ in the system as observed by confocal laser scanning microscopy (Figure S5). The Pickering droplets formed by using a ratio of oil to water of 0.5 and processed at a pressure of 7500 psi only contained $\mathrm{SiO}_{2} \mathrm{NCs}$ localized at the oil/water interface and displayed an average size of $8 \pm 3$ and $10 \pm 2 \mu \mathrm{m}$, when prepared with $\mathrm{CS}-\mathrm{SiO}_{2} \mathrm{NCs}$ and ALG- $\mathrm{SiO}_{2} \mathrm{NCs}$, respectively (Figure $3 \mathrm{c}, \mathrm{d}$ ). Because microfluidization is a form of high-pressure homogenization, the mechanical integrity of the $\mathrm{SiO}_{2} \mathrm{NCs}$ could have been impacted during the formation of the Pickering emulsion. However, the morphology of the $\mathrm{SiO}_{2} \mathrm{NCs}$ before and after the microfluidization process did not change (Figure S6).

The Pickering emulsion droplets stabilized with CS- and ALG-coated $\mathrm{SiO}_{2} \mathrm{NCs}$ were then embedded in a hydrophobic coating. First, the Pickering emulsion was mixed with a latex 
composed of $\mathrm{P}$ (MMA-co-BA) nanoparticles in a water suspension. The concentration of the linseed oil Pickering emulsion was varied from 1 to 5 to $15 \mathrm{wt} \%$. The resulting mixtures were drop-casted on glass slides. After drying, the composite coatings contained 5, 21, and up to 45 wt \% Pickering droplets. The integrity of the droplets was preserved in the coating, and the diameter of the Pickering droplets did not significantly change after being embedded in the coatings (Figure 4 and Table S1).

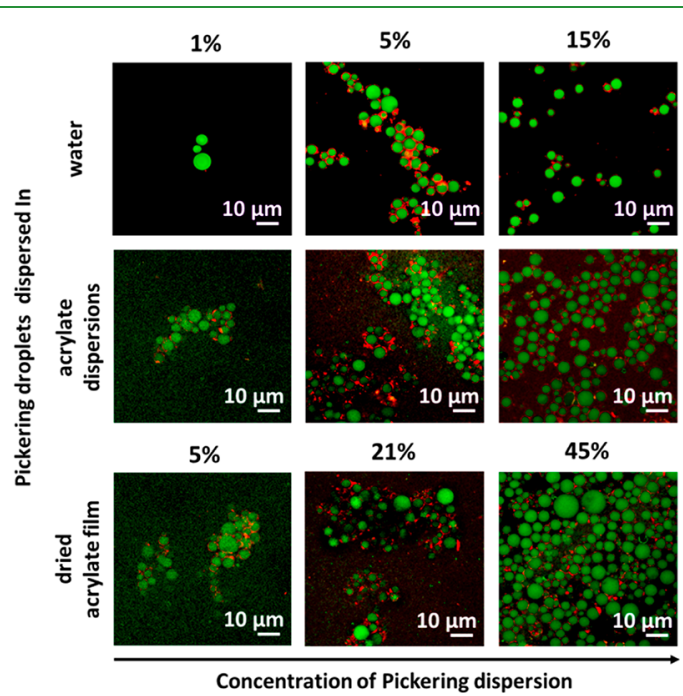

Figure 4. CLSM images of Pickering droplets in water (initially 1, 5, and $15 \mathrm{wt} \%)$, acrylate dispersions, and the corresponding dried acrylate film. The oil droplets were labeled with coumarin 6 (a green fluorescent dye), while the silica nanocapsules were labeled with Nile blue A (a red fluorescent dye).

The stability of Pickering droplets was investigated in emulsion and in the coatings. The appearance of Pickering emulsions was similar 10 days after their preparation, without phase separation (Figure S7). Coatings containing 45 wt \% linseed oil Pickering droplets were stored at $20{ }^{\circ} \mathrm{C}$ for 8 months and observed by confocal laser scanning microscopy (Figure S7). There was no significant difference in morphology and average diameter of Pickering droplets for the stored sample $(5 \pm 1 \mu \mathrm{m})$ compared to the fresh sample $(6 \pm 1 \mu \mathrm{m})$.

The composite coatings were immersed in buffer solutions at $\mathrm{pH} 3,7$, and 11 to investigate their $\mathrm{pH}$-responsive release of BTA from the coatings. As shown in Figure 5, the release of BTA from the coatings containing Pickering droplets was slower than the release of BTA from coatings containing macroemulsion of linseed oil droplets because $\mathrm{SiO}_{2} \mathrm{NCs}$ localized on the oil surface acted as a barrier to delay the release of BTA. Furthermore, the release of BTA from coatings with Pickering droplets stabilized with CS- and ALG-coated $\mathrm{SiO}_{2} \mathrm{NCs}$ showed a $\mathrm{pH}$ dependency. At a $\mathrm{pH}$ value of $3, \mathrm{CS}$ is highly protonated and soluble in water, leading to less stable Pickering droplets. In such acidic conditions, the release of BTA from the coating containing Pickering droplets stabilized with CS-coated $\mathrm{SiO}_{2} \mathrm{NCs}$ was faster than for the coatings where the Pickering droplets were stabilized with ALG-coated $\mathrm{SiO}_{2} \mathrm{NCs}$. Conversely, the release of BTA from the coating containing Pickering droplets stabilized with ALG-coated $\mathrm{SiO}_{2} \mathrm{NCs}$ was faster than stabilized with $\mathrm{CS}$-coated $\mathrm{SiO}_{2} \mathrm{NCs}$ at $\mathrm{pH} 7$ and 11 because Pickering droplets were destabilized by the electrostatic repulsion between $\mathrm{ALG}$ and $\mathrm{SiO}_{2} \mathrm{NCs}$. Furthermore, BTA $\left(\mathrm{p} K_{\mathrm{a}} \sim 8.2\right)^{48}$ has a high solubility in water at $\mathrm{pH} 7$ and 11, which promoted the release of BTA from the coating containing Pickering droplets stabilized with ALG-coated $\mathrm{SiO}_{2} \mathrm{NCs}$ which was completely released from the coating containing the macroemulsion after 2 days in neutral and basic conditions.

The anticorrosion performance of the coating was then investigated by using copper substrates. Typically, copper is corroded at a high rate in very strong alkaline solutions and at
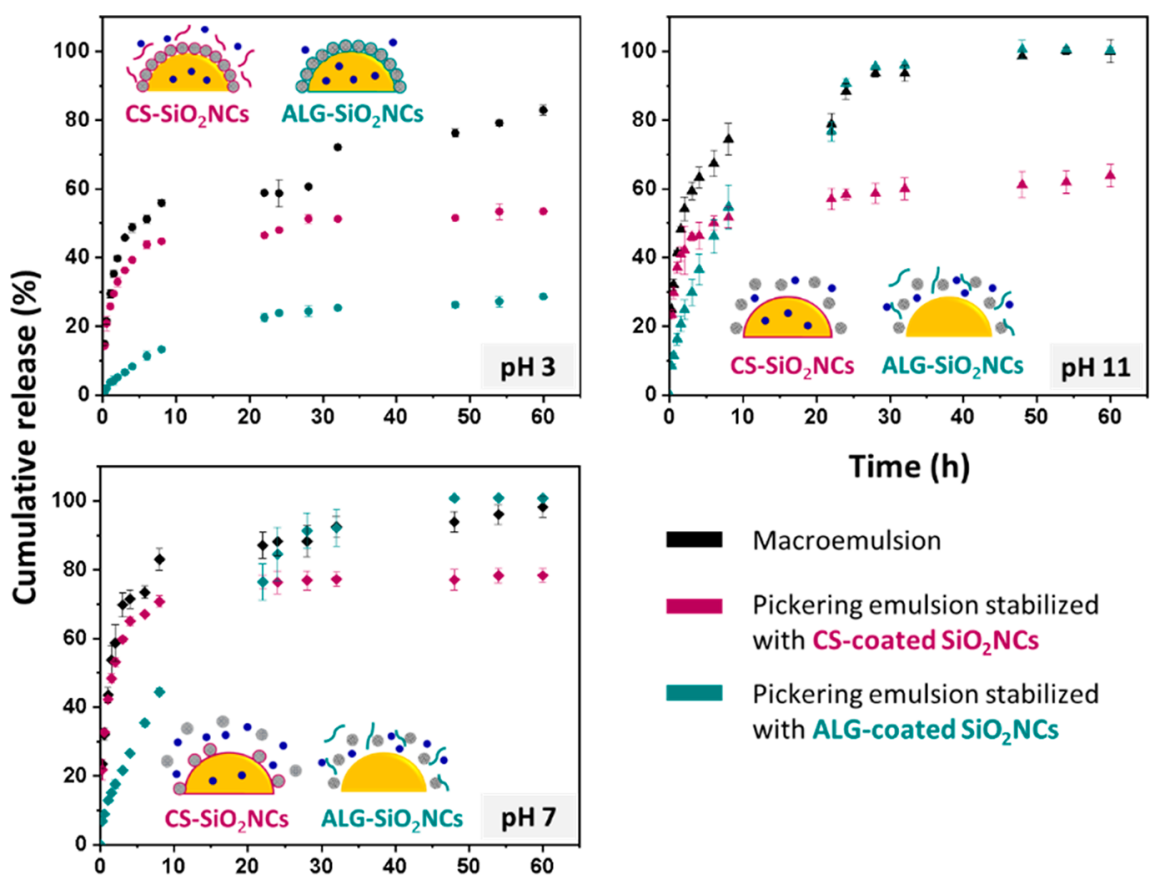

Figure 5. Release profiles of benzotriazole in buffer at a $\mathrm{pH}$ value of 3, 7, and 11 from coatings containing linseed oil macroemulsion and linseed oil Pickering droplets stabilized by chitosan- and alginate-coated silica nanocapsules. 

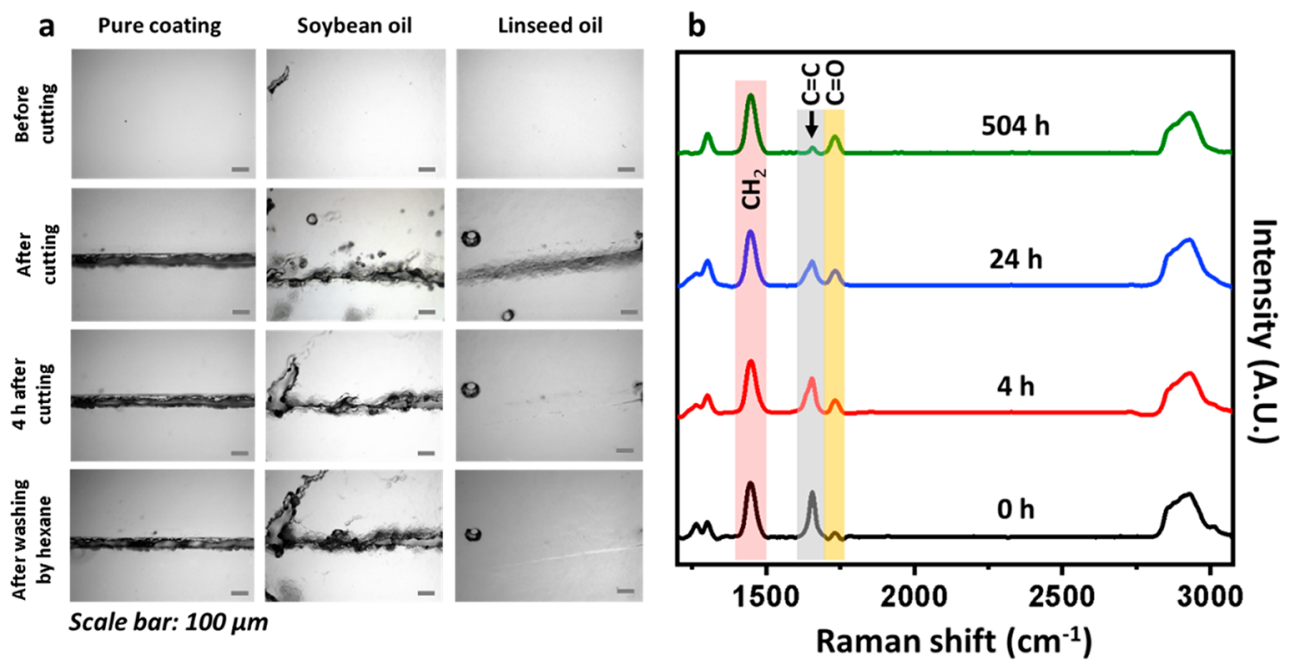

Figure 6. Investigation of the self-healing performance of the coatings. (a) Optical images of the acrylate coating, acrylate coatings containing 45 wt $\%$ soybean oil or linseed oil Pickering droplets before and after scratching the coating. (b) Raman spectra of the damaged acrylate coatings containing 45 wt \% linseed oil Pickering droplets after 0, 4, 24, and $504 \mathrm{~h}$.

a slow rate in acidic and neutral conditions. ${ }^{49}$ Therefore, the Pickering droplets stabilized with ALG-coated $\mathrm{SiO}_{2} \mathrm{NCs}$ were selected for the coatings on copper due to the fast release of BTA in basic conditions from these microdroplets. First, the self-healing performance of the coating containing linseed oil Pickering droplets was investigated. A control system where the linseed oil was substituted for soybean oil was also prepared. Glass surfaces covered with either pure P(MMA-co$\mathrm{BA})$ coating, $\mathrm{P}(\mathrm{MMA}-\mathrm{co}-\mathrm{BA})$ coating containing soybean oil Pickering droplets, and the $\mathrm{P}(\mathrm{MMA}-\mathrm{co}-\mathrm{BA})$ coating containing linseed oil Pickering droplets were incised. The evolution of the defect was monitored at $20{ }^{\circ} \mathrm{C}$ by optical microscopy. Already $4 \mathrm{~h}$ following the incision of the coatings, the damaged area on the coating containing linseed oil Pickering droplets was healed. In contrast, the damaged area on the other coatings remained visible (Figure 6a). Furthermore, the material covering the damaged area in the $\mathrm{P}(\mathrm{MMA}-$ co- $\mathrm{BA})$ coating containing linseed oil Pickering droplets could not be extracted when the surface was immersed in hexane, suggesting that linseed oil had polymerized. Indeed, the unsaturated esters present in linseed oil (oleic acid, linoleic acid, and linolenic acid $)^{50}$ are susceptible to oxidation upon exposure to the oxygen in the air, leading to their polymerization and the formation of a film. ${ }^{51,52}$ The formation of similar healed films has also been observed in the case of ruptured of polyureaformaldehyde capsules containing linseed oil. ${ }^{40,53}$ The healing of the coating containing linseed oil Pickering droplets was monitored by Raman spectroscopy. As shown in Figure 6b, the signal at $1654 \mathrm{~cm}^{-1}$, associated with the stretching of the aliphatic double bonds, decreased with time following the scratching of the coating. The integration of the $\mathrm{C}=\mathrm{C}$ stretching peak $\left(1615-1695 \mathrm{~cm}^{-1}\right)$, representing the amount of double bonds in the linseed oil, was used to monitor to polymerization of the unsaturated oil. After $24 \mathrm{~h}, 93 \%$ of the double bonds had been consumed, and after 3 weeks, only $0.75 \%$ of the double bonds were still present in the damaged area. To investigate the stability of the coating during storage, coatings on glass slides containing linseed oil Pickering droplets were kept at $25{ }^{\circ} \mathrm{C}$ and $67 \%$ humidity for 1,5 , and 10 days. The coatings were then scratched, and the coatings were allowed to heal for 1 day. The conversion of double bonds in the linseed oil was quantified by comparing the area of the $\mathrm{C}=\mathrm{C}$ vibration at $1654 \mathrm{~cm}^{-1}$ (between 1615 and 1695 $\mathrm{cm}^{-1}$ ) to the integral of the $\mathrm{C}=\mathrm{O}$ vibration at $1730 \mathrm{~cm}^{-1}$ (between 1710 and $1760 \mathrm{~cm}^{-1}$ ) (Figure S8). When the coating was stored for 1 day, $90 \%$ of the double bonds were consumed while a similar amount of double bonds (92\%) had been polymerized after the coatings were stored for 5 and 10 days. Therefore, the coatings were stable and allowed for healing after storage.

The ability of the damaged coatings for sensing corrosion was then studied by immersing coated copper substrates in a 3.5 wt $\% \mathrm{NaCl}$ aqueous solution. A blue color appeared on the copper substrates covered with a coating containing only $\mathrm{P}$ (MMA-co-BA) and $\mathrm{SiO}_{2} \mathrm{NCs}-\mathrm{TMB} 2 \mathrm{~h}$ after immersion (Figure $7 \mathrm{~b}$ ) while the coloration appeared after 2 days for samples coated with $\mathrm{P}(\mathrm{MMA}-c o-\mathrm{BA})$ containing linseed oil Pickering droplets (Figure $7 \mathrm{c}$ ). With prolonged immersion, the corrosion of the metal was also observed. Visible signs of corrosions appeared after 2 days of immersion for the copper plates coated with either pure $\mathrm{P}(\mathrm{MMA}-\mathrm{co}-\mathrm{BA})$ or a mixture of $\mathrm{P}$ (MMA-co-BA) and $\mathrm{SiO}_{2} \mathrm{NCs}-\mathrm{TMB}$. When the copper plates

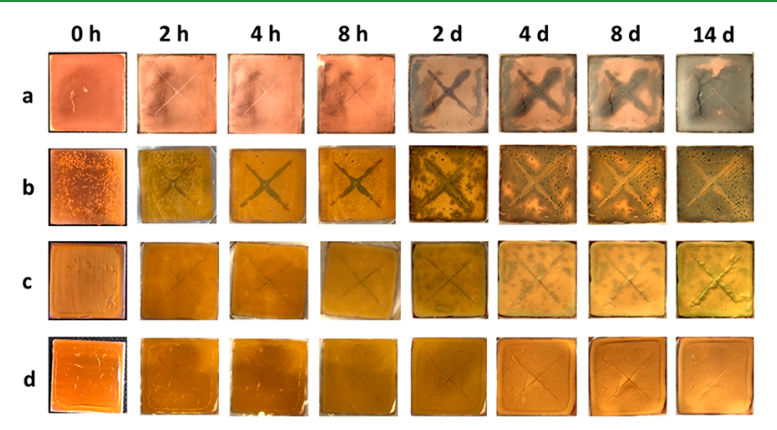

Figure 7. Photographs of the copper plates after immersion in $3.5 \mathrm{wt}$ $\% \mathrm{NaCl}$ aqueous solution. For copper plates coated with pure $\mathrm{P}$ (MMA-co-BA) (a), $\mathrm{P}$ (MMA-co-BA) containing alginate-coated silica nanocapsules with encapsulated thymol blue (b), P(MMA-co-BA) containing linseed oil Pickering droplets stabilized with ALG-coated $\mathrm{SiO}_{2} \mathrm{NCs}-\mathrm{TMB}$ (c), and P(MMA-co-BA) containing linseed oil Pickering droplets loaded with benzotriazole and stabilized with ALG-coated $\mathrm{SiO}_{2} \mathrm{NCs}-\mathrm{TMB}(\mathrm{d})$. 
were coated with pure $\mathrm{P}(\mathrm{MMA}-\mathrm{co}-\mathrm{BA})$, a black color, due to the formation of copper oxide, appeared without prior blue coloration (Figure $7 \mathrm{a}$ ) after 2 days of immersion. However, copper plates coated with $\mathrm{P}(\mathrm{MMA}-\mathrm{co}-\mathrm{BA})$ and the linseed oil Pickering emulsion only showed signs of corrosion after 14 days. Thus, coatings containing $\mathrm{SiO}_{2} \mathrm{NCs}$-TMB were able to sense an early stage of the corrosion, and coating containing both $\mathrm{SiO}_{2} \mathrm{NCs}$-TMB and linseed oil could delay the corrosion. Finally, the triple-functional coating (Figure $7 \mathrm{~d}$ ) containing the corrosion sensing $\mathrm{SiO}_{2} \mathrm{NCs}-\mathrm{TMB}$, the self-healing linseed oil, and the corrosion inhibitor BTA did not display any blue coloration, and no evidence of corrosion was observed for similar immersion time. The absence of corrosion and the absence of blue coloration occurring at the onset of corrosion can be ascribed to the anticorrosive effect of BTA. BTA is known to form a complex with copper ions during the corrosion process, leading to a protective barrier against oxygen adsorption and inhibition of further corrosion. ${ }^{41}$

To quantify the anticorrosion performance of the different coatings, potentiodynamic polarization (Figure 8 and Table

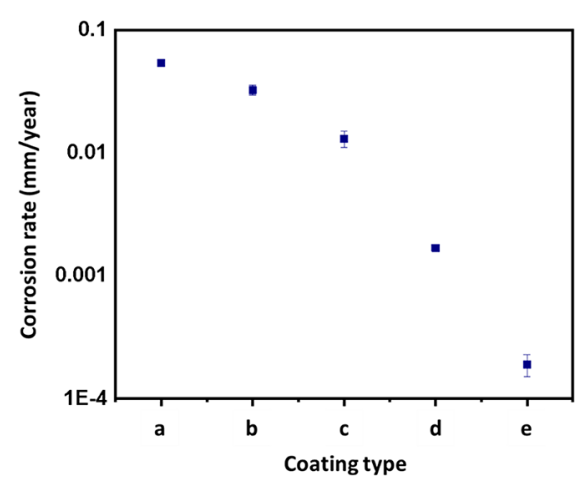

Figure 8. Corrosion rates of (a) bare copper and of copper coated with (b) pure acrylate coating or acrylate coating containing (c) alginate-coated silica nanocapsules with encapsulated thymol blue, (d) linseed oil Pickering droplets stabilized with alginate-coated silica nanocapsules with encapsulated thymol blue, or (e) benzotriazoleloaded linseed oil Pickering droplets stabilized with alginate-coated silica nanocapsules with encapsulated thymol blue.

S2) was used. The corrosion rates of bare copper, copper coated with the acrylate coating, and the acrylate coating containing $\mathrm{SiO}_{2} \mathrm{NCs}-\mathrm{TMB}$ were $(5.4 \pm 0.3) \times 10^{-2},(3.3 \pm$ $0.3) \times 10^{-2}$, and $(1.3 \pm 0.2) \times 10^{-2} \mathrm{~mm} \mathrm{year}^{-1}$, respectively. Moreover, the addition of linseed oil and BTA-loaded linseed oil Pickering droplets could reduce the corrosion rate of copper substrates to $(1.79 \pm 0.03) \times 10^{-3}$ and $(1.89 \pm 0.39) \times$ $10^{-4} \mathrm{~mm}$ year $^{-1}$. The corrosion rate of the acrylate coating containing BTA-loaded linseed oil Pickering droplets was reduced 284 times compared to the copper with no coating. Therefore, the corrosion rate measurements showed that the presence of linseed oil and BTA in the coating enhanced the protection of copper substrate against corrosion, and the presence of the new triple-functional Pickering additive alone reduced the corrosion rate 171 times compared to the pure acrylate coating. In addition, the coating containing Pickering droplets loaded with BTA showed a very high ratio of corrosion rate between bare copper and coated copper $(\mathrm{CR}=$ $284 \mathrm{~mm} /$ year $)$ and a low corrosion current density $\left(j_{\text {corr }}=\right.$ $\left.0.016 \mu \mathrm{A} / \mathrm{cm}^{2}\right)$. Considering that Pickering droplets are additives and not the matrix of the coating, the corrosion resistance of the coating created by the addition of this additive in a polymer coating is impressive and surpasses other additives (Table S3). Furthermore, the multifunctional Pickering droplets used here and the acrylate coating could potentially be used for other coatings matrices, which intrinsically possess better anticorrosion properties than the P(MMA-co-BA) used here.

The effect of linseed oil Pickering droplets loaded with benzotriazole on the anticorrosion and healing performance was further investigated by electrochemical impedance spectroscopy (EIS). The frequency dependence of impedance, expressed as Bode diagrams, can reveal the underlying corrosion process. The impedance modulus at $0.01 \mathrm{~Hz}$ $\left(Z_{f=0.01 \mathrm{~Hz}}\right)$ of Bode plots is usually considered as a measure of the anticorrosion performance of the coatings. Bode plots for copper coated with the acrylate coating, the acrylate coating containing linseed oil Pickering droplets, and acrylate coating containing linseed oil Pickering droplets loaded with benzotriazole were obtained after immersion of unscratched and scratched coatings in a $3.5 \mathrm{wt} \% \mathrm{NaCl}$ aqueous solution (Figure S9). The coatings without scratching did not show significant differences in impedance $\left(Z_{f=0.01 \mathrm{~Hz}} \sim 10^{10} \Omega \cdot \mathrm{cm}^{2}\right)$. After scratching, the impedance of the acrylate coating dramatically decreased. On the contrary, high impedance values were recovered with the coatings containing the Pickering droplets after 1 day due to the formation of polymerized linseed oil on the metal. Furthermore, the addition of BTA reduced the decrease of impedance after scratching (Figure S9c, $5 \mathrm{~min}$ ). Therefore, the coating containing Pickering droplets displayed a better anticorrosion performance than the neat acrylate coating.

The behavior of the coated copper samples revealed a causal relationship between the different functions of the coatings. In the samples coated P(MMA-co-BA) containing linseed oil Pickering droplets stabilized with ALG-coated $\mathrm{SiO}_{2} \mathrm{NCs}-\mathrm{TMB}$, once the stability of the Pickering droplets is lost due to either mechanical damages of the coating or a change in the acidity of the local environment, linseed oil is first released and polymerized; this happened within the first $4 \mathrm{~h}$ (Figure 6). Then, the color change can only be clearly identified after 2 days of immersion (Figure 7). This phenomenon is due to the fact that the color change occurred following the contact between hydroxide ions and the thymol blue molecules. Even though the silica nanocapsules prepared by an interfacial solgel process in miniemulsion typically present a pore size of 2$6 \mathrm{~nm},{ }^{54}$ the dye was mostly kept in the nanocapsules in the dispersions and in the coatings because of its very low solubility both in water and in the coating. Thus, the color change of the coating can only be observed when the corrosion induces an increase in the local concentration of hydroxide ions. Moreover, electrochemical impedance spectroscopy measurements (Figure S9) of samples coated with P(MMAco-BA) containing linseed oil Pickering droplets loaded with BTA and stabilized with ALG-coated $\mathrm{SiO}_{2} \mathrm{NCs}$-TMB showed that the effect of the corrosion inhibitor BTA can be observed before the effect of the healing induced by the reaction of the linseed oil. These results suggest an order of actions as follows: adsorption of BTA on the surface of the metal, formation of a healing layer through the reaction of linseed oil, and, finally, a visible color change. The rationale for such design is that corrosion should be detected in the case where it cannot be hindered anymore by the presence of the inhibitor or selfhealing agent. The change of color is then a sign for an operator to change the coating because of critical failure. 


\section{CONCLUSIONS}

In this work, we prepared multifunctional microcarriers that contain a corrosion sensor, a corrosion inhibitor, and a healing agent. The microcarriers could be synthesized by stabilizing linseed oil droplets containing benzotriazole with silica nanocapsules loaded with a responsive dye. The oil droplets were further stabilized with chitosan and alginate, which imparted the Pickering emulsions with a $\mathrm{pH}$-responsive character. Multifunctional coatings for anticorrosion were created by embedding the Pickering emulsion droplets $(\sim 10$ $\mu \mathrm{m})$ in a polymer matrix. Upon corrosion, the color of the coating turned blue, while both linseed oil and benzotriazole formed a protective barrier for the metal substrate and delayed the corrosion. Indeed, the corrosion rate of the multifunctional coating was reduced 171 times compared to the pristine acrylate coating. Furthermore, the coating could autonomously heal itself within $4 \mathrm{~h}$ after mechanical damage. Therefore, such a multifunctional coating showed great potential for anticorrosion but could also find applications in other fields such as biomedical devices or packaging.

\section{ASSOCIATED CONTENT}

\section{SI Supporting Information}

The Supporting Information is available free of charge at https://pubs.acs.org/doi/10.1021/acsami.0c11866.

TEM and SEM micrographs of the silica nanocapsules with encapsulated thymol blue $\left(\mathrm{SiO}_{2} \mathrm{NCs}-\mathrm{TMB}\right)$, photographs of the Pickering emulsions, $\zeta$ potential of $\mathrm{SiO}_{2} \mathrm{NCs}$ and polymer-coated $\mathrm{SiO}_{2} \mathrm{NCs}$, CLSM images of the oil droplets stabilized with alginate-coated $\mathrm{SiO}_{2} \mathrm{NCs}$, average diameters of Pickering droplets, corrosion potential $\left(E_{\text {corr }}\right)$, corrosion current density $\left(j_{\text {corr }}\right)$, and polarization resistance $\left(R_{\mathrm{p}}\right)$ of copper substrates, comparison of coating performance between our coating and the established coatings for copper substrate, Raman spectra of the damaged acrylate coating and Bode plots of the coated copper substrates. (PDF)

\section{AUTHOR INFORMATION}

\section{Corresponding Authors}

Daniel Crespy - Max Planck-VISTEC Partner Laboratory for Sustainable Materials, Department of Materials Science and Engineering, School of Molecular Science and Engineering, Vidyasirimedhi Institute of Science and Technology, Rayong 21210, Thailand; Email: daniel.crespy@vistec.ac.th

Héloïse Thérien-Aubin - Max Planck Institute for Polymer Research, 55128 Mainz, Germany; 이이.org/0000-00034567-516X; Email: therien@mpip-mainz.mpg.de

\section{Authors}

Kusuma Thongchaivetcharat - Max Planck-VISTEC Partner Laboratory for Sustainable Materials, Department of Materials Science and Engineering, School of Molecular Science and Engineering, Vidyasirimedhi Institute of Science and Technology, Rayong 21210, Thailand

Suttiruk Salaluk - Max Planck-VISTEC Partner Laboratory for Sustainable Materials, Department of Materials Science and Engineering, School of Molecular Science and Engineering, Vidyasirimedhi Institute of Science and Technology, Rayong 21210, Thailand
Katharina Landfester - Max Planck Institute for Polymer Research, 55128 Mainz, Germany; 이이.org/0000-00019591-4638

Complete contact information is available at:

https://pubs.acs.org/10.1021/acsami.0c11866

\section{Funding}

The Vidyasirimedhi Institute of Science and Technology (VISTEC) and the Max Planck Institute for Polymer Research for the Max Planck-VISTEC Partner Laboratory for Sustainable Materials, Thailand Research Fund (RSA6180063) and the Office of the Higher Education Commission of Thailand (OHEC).

\section{Notes}

The authors declare no competing financial interest.

\section{ACKNOWLEDGMENTS}

The authors are thankful for the financial support provided by the Vidyasirimedhi Institute of Science and Technology (VISTEC) and the Max Planck Institute for Polymer Research to the Max Planck-VISTEC Partner Laboratory for Sustainable Materials. D.C. acknowledges further the support of the Thailand Research Fund (RSA6180063) and the Office of the Higher Education Commission of Thailand (OHEC).

\section{REFERENCES}

(1) Koch, G.; Varney, J.; Thompson, N.; Moghissi, O.; Gould, M.; Payer, J. International Measures of Prevention, Application, and Economics of Corrosion Technologies Study; NACE International: Houston, TX, 2016.

(2) Shchukin, D. G.; Lamaka, S. V.; Yasakau, K. A.; Zheludkevich, M. L.; Ferreira, M. G. S.; Möhwald, H. Active Anticorrosion Coatings with Halloysite Nanocontainers. J. Phys. Chem. C 2008, 112 (4), 958964.

(3) Kartsonakis, I. A.; Balaskas, A. C.; Kordas, G. C. Influence of Cerium Molybdate Containers on the Corrosion Performance of Epoxy Coated Aluminium Alloys 2024-T3. Corros. Sci. 2011, 53 (11), 3771-3779.

(4) Wang, T.; Du, J.; Ye, S.; Tan, L.; Fu, J. Triple-Stimuli-Responsive Smart Nanocontainers Enhanced Self-Healing Anticorrosion Coatings for Protection of Aluminum Alloy. ACS Appl. Mater. Interfaces 2019, 11, 4425-4438.

(5) Maia, F.; Tedim, J.; Lisenkov, A. D.; Salak, A. N.; Zheludkevich, M. L.; Ferreira, M. G. S. Silica Nanocontainers for Active Corrosion Protection. Nanoscale 2012, 4 (4), 1287-1298.

(6) Abrantes Leal, D.; Wypych, F.; Bruno Marino, C. E. ZincLayered Hydroxide Salt Intercalated with Molybdate Anions as a New Smart Nanocontainer for Active Corrosion Protection of Carbon Steel. ACS Appl. Mater. Interfaces 2020, 12 (17), 19823-19833.

(7) Qian, H.; Xu, D.; Du, C.; Zhang, D.; Li, X.; Huang, L.; Deng, L.; Tu, Y.; Mol, J. M. C.; Terryn, H. A. Dual-Action Smart Coatings with a Self-Healing Superhydrophobic Surface and Anti-Corrosion Properties. J. Mater. Chem. A 2017, 5 (5), 2355-2364.

(8) Liu, C.; Jin, Z.; Cheng, L.; Zhao, H.; Wang, L. Synthesis of Nanosensors for Autonomous Warning of Damage and Self-Repairing in Polymeric Coatings. Nanoscale 2020, 12 (5), 3194-3204.

(9) Xu, J. B.; Cao, Y. Q.; Fang, L.; Hu, J. M. A. A One-Step Preparation of Inhibitor-Loaded Silica Nanocontainers for SelfHealing Coatings. Corros. Sci. 2018, 140, 349-362.

(10) Zhao, Y.; Berger, R.; Landfester, K.; Crespy, D. Double RedoxResponsive Release of Encoded and Encapsulated Molecules from Patchy Nanocapsules. Small 2015, 11 (25), 2995-2999.

(11) Seidi, F.; Druet, V.; Huynh, N.; Phakkeeree, T.; Crespy, D. Hemiaminal Ether Linkages Provide a Selective Release of Payloads from Polymer Conjugates. Chem. Commun. 2018, 54 (97), 1373013733. 
(12) Shchukina, E.; Wang, H.; Shchukin, D. G. NanocontainerBased Self-healing Coatings: Current Progress and Future Perspectives. Chem. Commun. 2019, 55 (27), 3859-3867.

(13) Huang, Y.; Deng, L.; Ju, P.; Huang, L.; Qian, H.; Zhang, D.; Li, X.; Terryn, H. A.; Mol, J. M. Triple-Action Self-Healing Protective Coatings Based on Shape Memory Polymers Containing DualFunction Microspheres. ACS Appl. Mater. Interfaces 2018, 10 (27), 23369-23379.

(14) Li, H.; Cui, Y.; Li, Z.; Zhu, Y.; Wang, H. Fabrication of Microcapsules Containing Dual-Functional Tung Oil and Properties Suitable for Self-Healing and Self-Lubricating Coatings. Prog. Org. Coat. 2018, 115, 164-171.

(15) Li, K.; Li, H.; Cui, Y.; Li, Z.; Ji, J.; Feng, Y.; Chen, S.; Zhang, M.; Wang, H. Dual-Functional Coatings with Self-Lubricating and Self-Healing Properties by Combining Poly(urea-formaldehyde)/ $\mathrm{SiO}_{2}$ Hybrid Microcapsules Containing Linseed Oil. Ind. Eng. Chem. Res. 2019, 58 (48), 22032-22039.

(16) Zhou, C.; Li, Z.; Li, J.; Yuan, T.; Chen, B.; Ma, X.; Jiang, D.; Luo, X.; Chen, D.; Liu, Y. Epoxy Composite Coating with Excellent Anticorrosion and Self-Healing Performances Based on MultiFunctional Zeolitic Imidazolate Framework Derived Nanocontainers. Chem. Eng. J. 2020, 385, 123835-123851.

(17) Habib, S.; Khan, A.; Nawaz, M.; Sliem, M. H. R.; Shakoor, R. A.; Kahraman, R.; Abdullah, A. M.; Zekri, A. Self-Healing Performance of Multi-Functional Polymeric Smart Coatings. Polymers 2019, 11 (9), 1519-1538.

(18) Wang, J. P.; Song, X.; Wang, J. K.; Cui, X.; Zhou, Q.; Qi, T.; Li, G. L. Smart-Sensing Polymer Coatings with Autonomously Reporting Corrosion Dynamics of Self-Healing Systems. Adv. Mater. Interfaces 2019, 6 (10), 1900055-1900062.

(19) Wang, J.-P.; Wang, J.-K.; Zhou, Q.; Li, Z.; Han, Y.; Song, Y.; Yang, S.; Song, X.; Qi, T.; Mohwald, H.; Shchukin, D.; Li, G. L. Adaptive Polymeric Coatings with Self-Reporting and Self-Healing Dual Functions from Porous Core-Shell Nanostructures. Macromol. Mater. Eng. 2018, 303 (4), 1700616-1700624.

(20) Chen, S.; Han, T.; Zhao, Y.; Luo, W.; Zhang, Z.; Su, H.; Tang, B. S.; Yang, J. A Facile Strategy to Prepare Smart Coatings with Autonomous Self-Healing and Self-Reporting Functions. ACS Appl. Mater. Interfaces 2020, 12 (4), 4870-4877.

(21) Grigoriev, D.; Shchukina, E.; Shchukin, D. G. Nanocontainers for Self-Healing Coatings. Adv. Mater. Interfaces 2017, 4, 16003181600328.

(22) Leal, D. A.; Riegel-Vidotti, I. C.; Ferreira, M. G. S.; Marino, C. E. B. Smart Coating Based on Double Stimuli-Responsive Microcapsules Containing Linseed Oil and Benzotriazole for Active Corrosion Protection. Corros. Sci. 2018, 130, 56-63.

(23) Zheludkevich, M. L.; Tedim, J.; Ferreira, M. G. S. "Smart" Coatings for Active Corrosion Protection Based on Multi-Functional Micro and Nanocontainers. Electrochim. Acta 2012, 82, 314-323.

(24) Bao, Y.; Zhang, Y.; Liu, P.; Ma, J.; Zhang, W.; Liu, C.; Simion, D. Novel Fabrication of Stable Pickering Emulsion and Latex by Hollow Silica Nanoparticles. J. Colloid Interface Sci. 2019, 553, 83-90.

(25) Li, J.; Feng, Q.; Cui, J.; Yuan, Q.; Qiu, H.; Gao, S.; Yang, J. SelfAssembled Graphene Oxide Microcapsules in Pickering Emulsions for Self-Healing Waterborne Polyurethane Coatings. Compos. Sci. Technol. 2017, 151, 282-290.

(26) Yi, H.; Deng, Y.; Wang, C. Pickering Emulsion-Based Fabrication of Epoxy and Amine Microcapsules for Dual Core SelfHealing Coating. Compos. Sci. Technol. 2016, 133, 51-59.

(27) Li, H.; Li, S.; Li, Z.; Zhu, Y.; Wang, H. Polysulfone/ $/ \mathrm{SiO}_{2}$ Hybrid Shell Microcapsules Synthesized by the Combination of Pickering Emulsification and the Solvent Evaporation Technique and Their Application in Self-Lubricating Composites. Langmuir 2017, 33 (49), 14149-14155.

(28) Chen, K.; Zhou, S.; Yang, S.; Wu, L. Fabrication of All-WaterBased Self-Repairing Superhydrophobic Coatings Based on UVResponsive Microcapsules. Adv. Funct. Mater. 2015, 25 (7), 10351041.
(29) Yi, H.; Yang, Y.; Gu, X.; Huang, J.; Wang, C. Multilayer Composite Microcapsules Synthesized by Pickering Emulsion Templates and Their Application in Self-Healing Coating. J. Mater. Chem. A 2015, 3 (26), 13749-13757.

(30) Lv, L.-P.; Zhao, Y.; Vilbrandt, N.; Gallei, M.; Vimalanandan, A.; Rohwerder, M.; Landfester, K.; Crespy, D. Redox Responsive Release of Hydrophobic Self-Healing Agents from Polyaniline Capsules. J. Am. Chem. Soc. 2013, 135, 14198-14205.

(31) Zhao, D.; Wang, M.; Xu, Y.; Zhang, Z.; Ge, X. The Fabrication and Corrosion Resistance of Benzotriazole-Loaded Raspberry-Like Hollow Polymeric Microspheres. Surf. Coat. Technol. 2014, 238, 1526

(32) Rule, J. D.; Sottos, N. R.; White, S. R. Effect of Microcapsule Size on the Performance of Self-Healing Polymers. Polymer 2007, 48 (12), 3520-3529.

(33) Keller, M. W.; Sottos, N. R. Mechanical Properties of Microcapsules Used in a Self-Healing Polymer. Exp. Mech. 2006, 46 (6), 725-733.

(34) Lamaka, S. V.; Taryba, M. G.; Zheludkevich, M. L.; Ferreira, M. G. Novel Solid-Contact Ion-Selective Microelectrodes for Localized Potentiometric Measurements. Electroanalysis 2009, 21 (22), 24472453.

(35) Visser, A. E.; Swatloski, R. P.; Rogers, R. D. PH-Dependent Partitioning in Room Temperature Ionic Liquids Provides a Link to Traditional Solvent Extraction Behavior. Green Chem. 2000, 2, 1-4.

(36) Lee, T. H.; Song, Y. K.; Park, S. H.; Park, Y. I.; Noh, S. M.; Kim, J. C. Dual Stimuli Responsive Self-Reporting Material for Chemical Reservoir Coating. Appl. Surf. Sci. 2018, 434, 1327-1335.

(37) Maia, F.; Tedim, J.; Bastos, A. C.; Ferreira, M. G. S.; Zheludkevich, M. L. Nanocontainer-Based Corrosion Sensing Coating. Nanotechnology 2013, 24 (41), 415502-415510.

(38) Juita; Dlugogorski, B. Z.; Kennedy, E. M.; Mackie, J. C. Low Temperature Oxidation of Linseed Oil: A Review. Fire Sci. Rev. 2012, 1, 3-38.

(39) Tatiya, P. D.; Hedaoo, R. K.; Mahulikar, P. P.; Gite, V. V. Novel Polyurea Microcapsules Using Dendritic Functional Monomer: Synthesis, Characterization, and Its Use in Self-healing and Anticorrosive Polyurethane Coatings. Ind. Eng. Chem. Res. 2013, 52 (4), 1562-1570.

(40) Suryanarayana, C.; Rao, K. C.; Kumar, D. Preparation and Characterization of Microcapsules Containing Linseed Oil and Its Use in Self-Healing Coatings. Prog. Org. Coat. 2008, 63 (1), 72-78.

(41) Finšgar, M.; Milošev, I. Inhibition of Copper Corrosion by 1,2,3-Benzotriazole: A Review. Corros. Sci. 2010, 52 (9), 2737-2749.

(42) Gattinoni, C.; Tsaousis, P.; Euaruksakul, C.; Price, R.; Duncan, D. A.; Pascal, T.; Prendergast, D.; Held, G.; Michaelides, A. Adsorption Behavior of Organic Molecules: A Study of Benzotriazole on $\mathrm{Cu}(111)$ with Spectroscopic and Theoretical Methods. Langmuir 2019, 35 (4), 882-893.

(43) Zhao, X.; Yu, G.; Li, J.; Feng, Y.; Zhang, L.; Peng, Y.; Tang, Y.; Wang, L. Eco-Friendly Pickering Emulsion Stabilized by Silica Nanoparticles Dispersed with High-Molecular-Weight Amphiphilic Alginate Derivatives. ACS Sustainable Chem. Eng. 2018, 6 (3), 41054114.

(44) Liu, M.; Chen, X.; Yang, Z.; Xu, Z.; Hong, L.; Ngai, T. Tunable Pickering Emulsions with Environmentally Responsive Hairy Silica Nanoparticles. ACS Appl. Mater. Interfaces 2016, 8 (47), 3225032258.

(45) Alison, L.; Demirörs, A. F.; Tervoort, E.; Teleki, A.; Vermant, J.; Studart, A. R. Emulsions Stabilized by Chitosan-Modified Silica Nanoparticles: $\mathrm{pH}$ Control of Structure-Property Relations. Langmuir 2018, 34 (21), 6147-6160.

(46) Cheng, Y.; Luo, X.; Payne, G. F.; Rubloff, G. W. Biofabrication: Programmable Assembly of Polysaccharide Hydrogels in Microfluidics as Biocompatible Scaffolds. J. Mater. Chem. 2012, 22, 76597666.

(47) Wyss, A.; von Stockar, U.; Marison, I. W. Production and Characterization of Liquid-Core Capsules Made from Cross-Linked 
Acrylamide Copolymers for Biotechnological Applications. Biotechnol. Bioeng. 2004, 86 (5), 563-572.

(48) Hart, D. S.; Davis, L. C.; Erickson, L. C.; Callender, T. M. Sorption and Partitioning Parameters of Benzotriazole Compounds. Microchem. J. 2004, 77 (1), 9-17.

(49) Groysman, A. In Corrosion for Everybody; Springer: New York, 2010.

(50) Nosal, H.; Nowicki, J.; Warzała, M.; Semeniuk, I.; Sabura, E. Synthesis and Characterization of Alkyd Resins Based on Camelina Sativa Oil, Glycerol and Selected Epoxidized Vegetable Oils as Functional Modifiers. Prog. Org. Coat. 2016, 101, 553-568.

(51) Jadhav, R. S.; Mane, V.; Bagle, A. V.; Hundiwale, D. G.; Mahulikar, P. P.; Waghoo, G. Synthesis of Multicore Phenol Formaldehyde Microcapsules and Their Application in Polyurethane Paint Formulation for Self-Healing Anticorrosive Coating. Int. J. Ind. Chem. 2013, 4, 31-37.

(52) Kalita, D. J.; Tarnavchyk, I.; Sibi, M.; Moser, B. R.; Webster, D. C.; Chisholm, B. J. Biobased Poly(vinyl ether) Derived from Soybean Oil, Linseed Oil, and Camelina Oil: Synthesis, Characterization, and Properties of Crosslinked Networks and Surface Coatings. Prog. Org. Coat. 2018, 125, 453-462.

(53) Selvakumar, N.; Jeyasubramanian, K.; Sharmila, R. Smart Coating for Corrosion Protection by Adopting nano Particles. Prog. Org. Coat. 2012, 74 (3), 461-469.

(54) Jiang, S.; Prozeller, D.; Pereira, J.; Simon, J.; Han, S.; Wirsching, S.; Fichter, M.; Mottola, M.; Lieberwirth, I.; Morsbach, S.; Mailänder, V.; Gehring, S.; Crespy, D.; Landfester, K. Controlling Protein Interactions in Blood for Effective Liver Immunosuppressive Therapy by Silica Nanocapsules. Nanoscale 2020, 12 (4), 2626-2637. 